\title{
Article \\ Effects of Environmental Stresses (Heat, Salt, Waterlogging) on Grain Yield and Associated Traits of Wheat under Application of Sulfur-Coated Urea
}

\author{
Adil Altaf ${ }^{1}\left(\mathbb{D}\right.$, Xinkai Zhu ${ }^{1,2,3, *}$, Min Zhu ${ }^{1,2, *}$, Ma Quan ${ }^{1}$, Sana Irshad ${ }^{4}$, Dongyi Xu ${ }^{1}$, Muhammad Aleem ${ }^{5}$ (D), \\ Xinbo Zhang ${ }^{1}$, Sadia Gull ${ }^{6}$, Fujian Li $^{1}$, Amir Zaman Shah ${ }^{6}$ and Ahmad Zada ${ }^{7}$ (D)
}

check for updates

Citation: Altaf, A.; Zhu, X.; Zhu, M.; Quan, M.; Irshad, S.; Xu, D.; Aleem,

M.; Zhang, X.; Gull, S.; Li, F.; et al. Effects of Environmental Stresses (Heat, Salt, Waterlogging) on Grain Yield and Associated Traits of Wheat under Application of Sulfur-Coated Urea. Agronomy 2021, 11, 2340. https://doi.org/10.3390/ agronomy 11112340

Academic Editor: Juan M. Ruiz

Received: 26 October 2021

Accepted: 15 November 2021

Published: 19 November 2021

Publisher's Note: MDPI stays neutral with regard to jurisdictional claims in published maps and institutional affiliations.

Copyright: (c) 2021 by the authors. Licensee MDPI, Basel, Switzerland. This article is an open access article distributed under the terms and conditions of the Creative Commons Attribution (CC BY) license (https:// creativecommons.org/licenses/by/ $4.0 /)$.
1 Jiangsu Key Laboratory of Crop Genetics and Physiology, Jiangsu Key Laboratory of Crop Cultivation and Physiology, Wheat Research Center, College of Agriculture, Yangzhou University, Yangzhou 225009, China; er.altafadil@outlook.com (A.A.); mq_agriculture@163.com (M.Q.); xudongyi0923@163.com (D.X.); zhxb202@126.com (X.Z.); fjli_agriculture@163.com (F.L.)

2 Co-Innovation Center for Modern Production Technology of Grain Crops, Yangzhou University, Yangzhou 225009, China

3 Joint International Research Laboratory of Agriculture and Agri-Product Safety, The Ministry of Education of China, Yangzhou University, Yangzhou 225009, China

4 School of Environmental Studies, China University of Geosciences, Wuhan 430074, China; sanairshad55@gmail.com

5 College of Environment, Hohai University, Nanjing 210098, China; mmaleem@hotmail.com

6 College of Horticulture and Plant Protection, Yangzhou University, Yangzhou 225009, China; sadiagull137@yahoo.com (S.G.); dh18052@yzu.edu.cn (A.Z.S.)

7 College of Bioscience and Biotechnology, Yangzhou University, Yangzhou 225009, China; dh19025@yzu.edu.cn

* Correspondence: xkzhu@yzu.edu.cn (X.Z.); minzhu@yzu.edu.cn (M.Z.)

\begin{abstract}
Abiotic stresses, such as heat, salt, waterlogging, and multiple-stress environments have significantly reduced wheat production in recent decades. There is a need to use effective strategies for overcoming crop losses due to these abiotic stresses. Fertilizer-based approaches are readily available and can be managed in all farming communities. This research revealed the effects of sulfur-coated urea (SCU, $130 \mathrm{~kg} \mathrm{ha}^{-1}$, release time of 120 days) on wheat crops under heat, salt, waterlogging, and combined-stress climatic conditions. The research was done using a completely randomized design with three replicates. The results revealed that SCU at a rate of $130 \mathrm{~kg}$ of N ha showed a significantly ( $p \leq 0.05$ ) high SPAD value (55) in the case of waterlogging stress, while it was the lowest (31) in the case of heat stress; the control had a SPAD value of 58. Stress application significantly $(p \leq 0.05)$ reduced the leaf area and was the highest in control $\left(1898 \mathrm{~cm}^{2}\right)$, followed by salt stress $\left(1509 \mathrm{~cm}^{2}\right)$, waterlogging $\left(1478 \mathrm{~cm}^{2}\right)$, and heat stress $\left(1298 \mathrm{~cm}^{2}\right)$. A significantly $(p \leq 0.05)$ lowest crop yield was observed in the case of heat stress $\left(3623.47 \mathrm{~kg} \mathrm{ha}^{-1}\right)$ among all stresses, while it was $10,270 \mathrm{~kg} \mathrm{ha}^{-1}$ in control and was reduced up to $35 \%$ after the application of heat stress. Among all stresses, the salt stress showed the highest crop yield of $5473.16 \mathrm{~kg} \mathrm{ha}^{-1}$. A significant correlation was observed among growth rate, spike length, yield, and physiological constraints with $\mathrm{N}$ content in the soil. The SCU fertilizer was the least effective against heat stress but could tolerate salt stress in wheat plants. The findings suggested the feasibility of adding SCU as an alternative to normal urea to alleviate salt stresses and improve wheat crop growth and yield traits. For heat stress tolerance, the applicability of SCU with a longer release period of $\sim 180$ days is recommended as a future prospect for study.
\end{abstract}

Keywords: abiotic stresses; winter wheat; photosynthetic activity; morphological parameters; controlled-release nitrogen fertilizer 


\section{Introduction}

Feeding the world's growing population necessitates having a greater focus on the efficient and particular use of scarce resources, such as fertilizers. The yield of crops decreases due to various abiotic parameters, such as drought stress, salt stress, late sowing, poor seed quality, climate change, and lack of fertilizer [1-5]. High-temperature stress is the primary environmental issue that confines the yield of wheat. For every $1{ }^{\circ} \mathrm{C}$ increase in average temperature from $23^{\circ} \mathrm{C}$, the wheat yield will decrease by about $10 \%$ [6]. Heat stress significantly reduces the photosynthetic rate, chlorophyll content, leaf areas, and grain weight, and ultimately crop yield per hector is reduced to half [7-9]. Besides this, $>40 \%$ of the world's total wheat area is facing abiotic stress. The productivity of wheat is often unfavorably affected by salt stress, which has been linked to slow growth, changes in reproductive behavior, variations in enzymatic activity, damage to photosynthesis, injury to the ultrastructure of cell components, serotonin deficiency, and oxidative stress [10]. Many studies in the past have revealed the adverse effects of salt stress on the physiological traits of numerous plants, including cardoon genotypes [11], pepper [12], Vicia faba [13], and Olea europea L. [14]. Besides this, drought stress reduces morphological traits, such as leaf size and vegetative growth; physiological traits, such as reduction in photosynthesis and stomatal conductance; and the transpiration rate [15]. Drought stress has also been observed to alter the biochemical and physiological responses of wheat [7]. On the other hand, waterlogging is also a significant factor influencing the yield and quality of wheat. Waterlogging stress reduces yield, number of ears per square meter, grain weight, protein content, and levels of chlorophyll a and b while increasing proline levels [16]. Similarly, waterlogging induced a stress-activated antioxidant response system in Phalaris arundinacea [17]. In another study, long-term waterlogging stress affected photosynthetic traits such as leaf area, stomatal density, and stomatal conductance in apple cultivars [18]. So, the wheat yield has been reduced in recent years, resulting in price volatility and food insecurity. It has been proposed that wheat production must be increased by $60 \%$ to fulfill the needs of 9 billion people by $2050[4,5]$. This will necessitate an increase in annual wheat production of at least $1.6 \%$, which will require resistance to abiotic and biotic stresses and enhanced input use efficiency.

Many approaches have been used to reduce the deleterious effects of abiotic stress in plants; one of these approaches is the use of nitrogen $(\mathrm{N})$ fertilizer. The rational use of chemical fertilizers is essential for wheat production, food security, and the environment Nitrogen has been reported to enhance wheat crop yields [19]. Nitrate is a communal form of $\mathrm{N}$ that exists in cell vacuoles and is reduced by nitrate and nitrite reductase activities in the cytoplasm. Leaves contain chlorophyll, which is responsible for photosynthesis. When $\mathrm{N}$ is readily available in the soil solution, the nitrogen use efficiency of the plant is critical [20]. The excessive use of nitrogen fertilizer causes environmental pollution, as well as economic losses. The unwise use of nitrogen fertilizers can cause crop lodging and reduce economic yields. Thus, studying nitrogen for a good yield and time is inevitable for the wheat crop, especially once grown under stress conditions [21].

At the same time, loss of $\mathrm{N}$ is the main threat of environmental pollution, which causes health problems. The volatilization of ammonia in urea fertilizer is up to $65 \%$, depending on the environment and soil characteristics. Nitrate pollution produces serious health problems for humans and animals. The use of nitrogen higher than the crop requirement may be the reason for a low nitrogen utilization rate and nitrogen loss in the soil [19]. Hence, in order to reduce the loss of nitrogen under abiotic stress and increase the yield, it is recommended to use the $4 \mathrm{R}$ principle (right time, right amount, right source, and right place) for fertilization [22]. In this regard, slow-release nitrogen fertilizers can improve the tolerance of abiotic stresses $[19,21]$. Slow-release nitrogen fertilizer technology could be used to decrease water and environmental pollution [22]. Slow-release fertilizers contain a semipermeable layer of various essential oils, as well as secondary and significant nutrients, and control particle water solubility by slowing the hydrolysis procedure of water-soluble fertilizers. 
One of the good slow-release nitrogen fertilizers is sulfur-coated urea (SCU), which promotes wheat growth and development. The wheat crop has a positive correlation between " $\mathrm{S}$ " and " $\mathrm{N}$ " elements [23]. The S element is a secondary and fungicide with acidic possessions that neutralize the alkalinity of soil [24]. As a result, the excessive application of $\mathrm{N}$ without the $\mathrm{S}$ coating material results in the extreme leaching of $\mathrm{N}$ [21]. As a result, the prudent application of nitrogen fertilizers and nitrogen sources reduces strength while increasing crop yield under stress.

Few studies have narrated the effects of SCU on wheat under comparative examination of heat, salt stress, waterlogging and combined stress conditions. A study addressing the comparative effect of slow-release nitrogen fertilizer on three stresses (salt, waterlogging, and heat) has not been conducted before, hence the novelty of our study. There is a need to conduct a detailed study based on various abiotic conditions under controlled nitrogen fertilization. To address all the issues mentioned above, the current study aimed to determine the effects of salt stress, waterlogging, and heat stresses on the physiological attributes and wheat crop yield. Furthermore, the current study also focused on improving wheat growth and development, as well as viable soil management using SCU (with a nitrogen release period of 120 days) under heat, salt stress, waterlogging, and combined stresses. Another objective of the current study was to assess the effect of the $\mathrm{N}$ source and release rate on wheat production and abiotic stress tolerance. The effectiveness of slowrelease SCU against various abiotic stresses was determined along with control wheat with the same SCU fertilizer. This study also aimed to determine the key physical parameters affecting crop yield once the stresses were applied.

\section{Materials and Methods}

\subsection{Experimental Site and Environmental Conditions:}

Pot experiments were carried out during the wheat growing season in 2020-2021 (2021) at the Agricultural Experiment Station $\left(32^{\circ} 39^{\prime} \mathrm{N}, 119^{\circ} 42^{\prime} \mathrm{E}\right)$ of Agricultural College, Yangzhou University, in China. Winter wheat (Yangmai 25) was grown in the pot field. Each experiment consisted of five developmental phases (overwintering, jointing, booting, flowering, and maturity), with 6 seeds of Yangmai 25 genotype grown in individual pots (Figure S2). Four stresses were chosen: waterlogging, salt stress, heat, and the combined effect of these three stresses, which were monitored at different growth stages (Figure S3). Due to the abundant rainfall in this area, we did not need to irrigate during the wheat growing season. However, if necessary, the pots were irrigated with tap water accordingly to retain the field capacity required for healthy wheat growth.

The experiment was a completely randomized design with SCU treatment (controlSCU only) as the main plot and stress as the subplot. There were four stress treatments (waterlogging, salt stress, heat, and combined). There were five plots in the experiment (Figure S2). Each treatment was conducted in triplicate and was subjected to the same field management. The $\mathrm{N}$ rate adopted in the experiment was $130 \mathrm{~kg} \mathrm{ha}^{-1}$, consistent with the optimum $\mathrm{N}$ rate in all the treatments, including control (CK). Phosphate $\left(114 \mathrm{~kg} \mathrm{ha}{ }^{-1} \mathrm{P}_{2} \mathrm{O}_{5}\right)$ and potassium $\left(62 \mathrm{~kg} \mathrm{ha}^{-1} \mathrm{~K}_{2} \mathrm{O}\right)$ fertilizers were applied once before sowing conferring to the pre-soil analysis report. Basal fertilizer was applied at a depth of 10-15 cm [22]. A total of six seeds of Yangmai 25 were sown in a $10 \mathrm{~kg}$ pot filled with a standard potting mixture [25] (Table S2).

The slow-release sulfur-coated urea (SCU; release time 120 days) was used as a stressalleviation substance at a recommended dose of $130 \mathrm{~kg} \mathrm{ha}^{-1}$ in all treatments, including the control. Seeds were sown on 8 November 2020, while sampling was performed at the overwintering stage (28 December 2020), jointing stage (12 March 2021), booting stage (30 Mar 2021), flowering stage (17 April 2021), and maturity stage (28 May 2021). The setups for the different abiotic stress applications were established as follows.

For the heat stress, plants were upraised with control plants until the flowering stage and then moved to the heat stress chamber (cryogenic room) for the remainder of the growth period (up to maturity). The plants were kept under a $16 \mathrm{~h}$ photoperiod duration 
and provided a light intensity of $350 \mu \mathrm{mol} \mathrm{m} \mathrm{m}^{-2} \mathrm{~s}^{-1}$ generated by metal halide lamps. The temperature treatment was as follows: the night temperature was kept at $20^{\circ} \mathrm{C}$, whereas the day temperature was gradually increased to $33{ }^{\circ} \mathrm{C}$ and held for $8 \mathrm{~h}$, then subsequently decreased to $20{ }^{\circ} \mathrm{C}$. The relative humidity (\%RH) was kept at $64-68 \%$ and $76 \%$ during the day and night, respectively, in the stress chamber (Figures S1 and S3).

For waterlogging stress, plants were grown with control plants, and stress was applied from germination to the overwintering stage (35 days). Waterlogging was applied using water from a nearby water service by flooding the pots allocated for the waterlogging treatments. The soil was moisturized using water above field capacity using incessant flooding, generally every day, to produce an oxygen-deficient atmosphere. For this purpose, pots were placed in a water basin (i.e., used for nursery rice growing). There was a storage tank on one side and a drainage valve on the other side. The standing water level was maintained at $\sim 12 \mathrm{~cm}$. Water was replaced after 4-7 days according to weather and water conditions. For replacing water, a drainage valve was opened according to the storage tank valve so that the water level could be maintained. The soil moisture content was measured by an oven-drying method using $1 \mathrm{~g}$ of soil sample at $105^{\circ} \mathrm{C}$ overnight [26]. In control, the soil moisture content was $<85 \%$, while it was from 85 to $100 \%$ for the stressed plants (Figures S1 and S3).

For salt stress, a $15 \mathrm{mM}$ sodium chloride $(\mathrm{NaCl})$ solution was used as a source, while plants were grown with control plants under the same conditions. The salt stress was applied after the jointing stage and continued until maturation (Figures S1 and S3).

For combined stress, plants were grown in waterlogged stress, and after the jointing stage, salt stress was applied. After the flowering stage, these plants were transferred to the heating chamber, and they continued to grow there until the maturation stage (Figure S3). In total, the experimental setup consisted of 1 genotype $\times 3$ pots $\times 4$ abiotic stresses $\times 5$ developmental stages $\times 1$ fertilizer (SCU: for all treatments including control) $\times 6$ seeds per pot.

A control treatment was also established in triplicate in a separate plot containing the same SCU fertilizer but at a recommended dose of $130 \mathrm{~kg} \mathrm{ha}^{-1}$ (Figure S2). A separate pot experiment without any stress and fertilizer was also conducted under the same conditions to compare the nitrogen accumulation. Seeds were sown on 8 November 2020, and the wheat crop was harvested on 28 May 2021. During this study period, samples were collected at 5 stages: (1) overwintering stage: 28 December 2020; (2) jointing stage: 12 March 2021; (3) booting stage: 30 March 2021; (4) flowering stage: 17 April 2021; and (5) maturity stage: 28 May 2021.

\subsection{Procedure/Protocols for Growth and Yield Parameters}

Each experimental unit was measured for yield and yield-related characteristics, such as plant height, seeds per spike, total dry matter $\left(\mathrm{kg} \mathrm{ha}^{-1}\right)$, number of tillers per plant, grain yield ( $\mathrm{kg} \mathrm{ha}^{-1}$ ), average seeds weight per spike, and harvest index. Portable chlorophyll meters (SPAD-502, Konica Minolta, Osaka, Japan) and mobile photosynthesis systems (LI-6400, LI-COR Biosciences, Lincoln, NE 68504, USA) were used to collect data on physiological parameters, including chlorophyll content percent and net photosynthetic rate [26,27]. Wheat plants were harvested at various stages of development to measure fresh and dry biomass. An electrical weight balance was used to measure the fresh weight of leaves and stems. Then, oven drying of leaves and stems was done for $48 \mathrm{~h}$ (up to constant weight) at $70^{\circ} \mathrm{C}$, and the dry weight was calculated [24]. A leaf area meter (Model, CI-202, CID Bio-Science, Inc., 1554 NE 3rd Avenue, Camas, WA 98607, USA) was used to calculate the leaf area. At maturity, plants from three pots were collected from each experimental component, and various yield components were quantified. The final yield and biomass of the entire experimental unit were assessed separately, and on the rationale of dry biomass production, transformed into $\mathrm{kg} \mathrm{ha}^{-1}$. The activity of photosynthetic properties, fluorescence, photosynthetic rate, stomatal conductance, the intercellular $\mathrm{CO}_{2}$ concentration of the plants, transpiration rate, and water use efficiency were all measured 
with a portable system (LI-6400, Li-Cor Inc., USA). Water use efficiency was also calculated (photosynthetic rate divided by transpiration rate) following the methodology of a previous study [24]. All analyses were performed in triplicate, and mean values were calculated.

\subsection{Estimation of Plant NPK}

The plant $\mathrm{N}$ content was measured at 20,60, and 120 days using the standard procedure described by Watson et al. [24]. A digestion tube was filled with the plant-dried sample $(1.0 \mathrm{~g})$. Then, in a digestion block, $15 \mathrm{~mL}$ of concentrated $\mathrm{H}_{2} \mathrm{SO}_{4}$ and $1 \mathrm{~g}$ digestion mixture $\left(\mathrm{K}_{2} \mathrm{SO}_{4}+\mathrm{CuSO}_{4} @ 9: 1\right)$ were combined, and the tubes were heated for $2 \mathrm{~h}$ at $450{ }^{\circ} \mathrm{C}$. After heating, the color of the solution was changed from transparent to yellowishgreen, visible in the digestion tubes. A distillate unit produced the required volume for the distillation process. Then, the material was placed in a receiver containing $4 \%$ boric acid $(25 \mathrm{~mL})$. After that, a few drops of the indicator were added; the purple color then changed to golden yellow through the distillation process. The subsequent distillates were then titrated with $0.1 \mathrm{~N} \mathrm{H}_{2} \mathrm{SO}_{4}$, resulting in purple as an endpoint from a golden yellow shade [24].

The following spectrophotometer and the spectrophotometric vanadium phosphomolybdate processes were used to estimate the $P$ percent in the plant following the standard protocol of a previous study [28]. The spectrophotometer was used to run the standard of $\mathrm{P}$ samples. Following this, the $\mathrm{P}$ concentration of plant samples was assessed using the yellow color procedure. The digested plant samples were used to distill water, and a coloring reagent was placed in a flask. The flask was then placed at room temperature for about 30-35 $\mathrm{min}$, with the development of color over the subsequent time. The $\mathrm{P}$ percent in plant samples was then calculated using just a spectrophotometer at $420 \mathrm{~nm}$ using the standard method [29]. The flame photometer procedure was used to measure the $\mathrm{K}$ concentration using a method developed by a previous study [30].

\subsection{Statistical Analysis}

Statistical analyses were performed with SPSS 16.0 (SPSS Inc., Chicago, IL, USA) [31]. All results are presented as the means of three replicates. Data from each sampling stage were analyzed separately and were subjected to one-way analysis of variance (ANOVA) followed by means comparison using Duncan's multiple range test (DMRT) using a statistically significant level of $p<0.05$. In the correlation analysis, the nonparametric Spearman test was used for the correlation of different traits.

\section{Results}

Wheat (Triticum aestivum L.), a staple cereal crop in various world regions, is a major cereal crop subjected to many biotic and abiotic stresses such as heat, salt, waterlogging, and sometimes, a combination of stresses. These stresses have a global impact on crop yields. Farmers have used various mechanisms to combat a vast array of biotic and abiotic stresses. One of these aspects is fertilizers that affect the nutrient availability to the plant. The experiment was conducted on winter wheat crop Yangmai 25 genotype for a fivestage (germination to maturity) growth period amended with SCU having a release time of 120 days. The sample and experimental analysis were conducted at every stage. The effect of SCU or stress alleviation effect of SCU was analyzed in terms of growth and physiological parameters. The study showed exciting aspects of each type of stress that are presented below.

\subsection{Plant Growth Study under Abiotic Stress Amended with SCU}

\subsubsection{Waterlogging Stress and Wheat Growth during the Study}

The waterlogging stress was applied up to the overwintering stage; initially, stress did not affect plant growth significantly $(p \leq 0.05)$. It was evident in the change of florescence value and photosynthetic rate (Figure $1 \mathrm{a}, \mathrm{b}$ ), which were 0.794 and $14.58 \mu \mathrm{mol} \mathrm{CO}_{2} \mathrm{~m}^{-2} \mathrm{~s}^{-1}$, respectively, at the start of the experiment. At the flowering stage, a significant $(p \leq 0.05)$ 
change of $\sim 5 \%$ was observed in the florescence value, and the photosynthetic rate was decreased by $7 \%$, compared to the control. This was also related to the number of tillers and leaf area of the plants (Figures 2 and 3 ), which were also significantly $(p<0.05)$ lower than the control. At the flowering stage, the plant had four tillers in the case of stress, while the control had five; the leaf area of the control plant was $1898 \mathrm{~cm}^{2}$, while it was $1330 \mathrm{~cm}^{2}$ in stress conditions. The photosynthetic rate corresponded to the SPAD value, which showed a significant $(p<0.05)$ decrease at the flowering stage (Figure 4$)$. At the flowering stage, it was $\sim 57$ in the case of the control and $\sim 50$ once waterlogging stress was applied, i.e., a decrease of $10 \%$ was observed. The SPAD value is a measure of the chlorophyll value. Both leaf area and photosynthetic rate were negatively affected by stress, consequently reducing total dry matter accumulation rates and final yields. The same trend of fresh and dry biomass was observed in our study, where stress application considerably $(p \leq 0.05)$ reduced the biomass content of the wheat plant (Figures 5 and 6 ). This significant $(p \leq 0.05)$ decrease in the photosynthetic rate was also correlated with the stomatal conductance (Figure $7 \mathrm{~b}$ ), transpiration rate (Figure 7a), and water use efficiency (Figure 7c). In April 2021, stressed wheat plants showed 9, 10, 8.8, and 9.6\% lower stomatal conductance, transpiration rate, intercellular $\mathrm{CO}_{2}$, and water use efficiency, respectively, compared to the control plant.
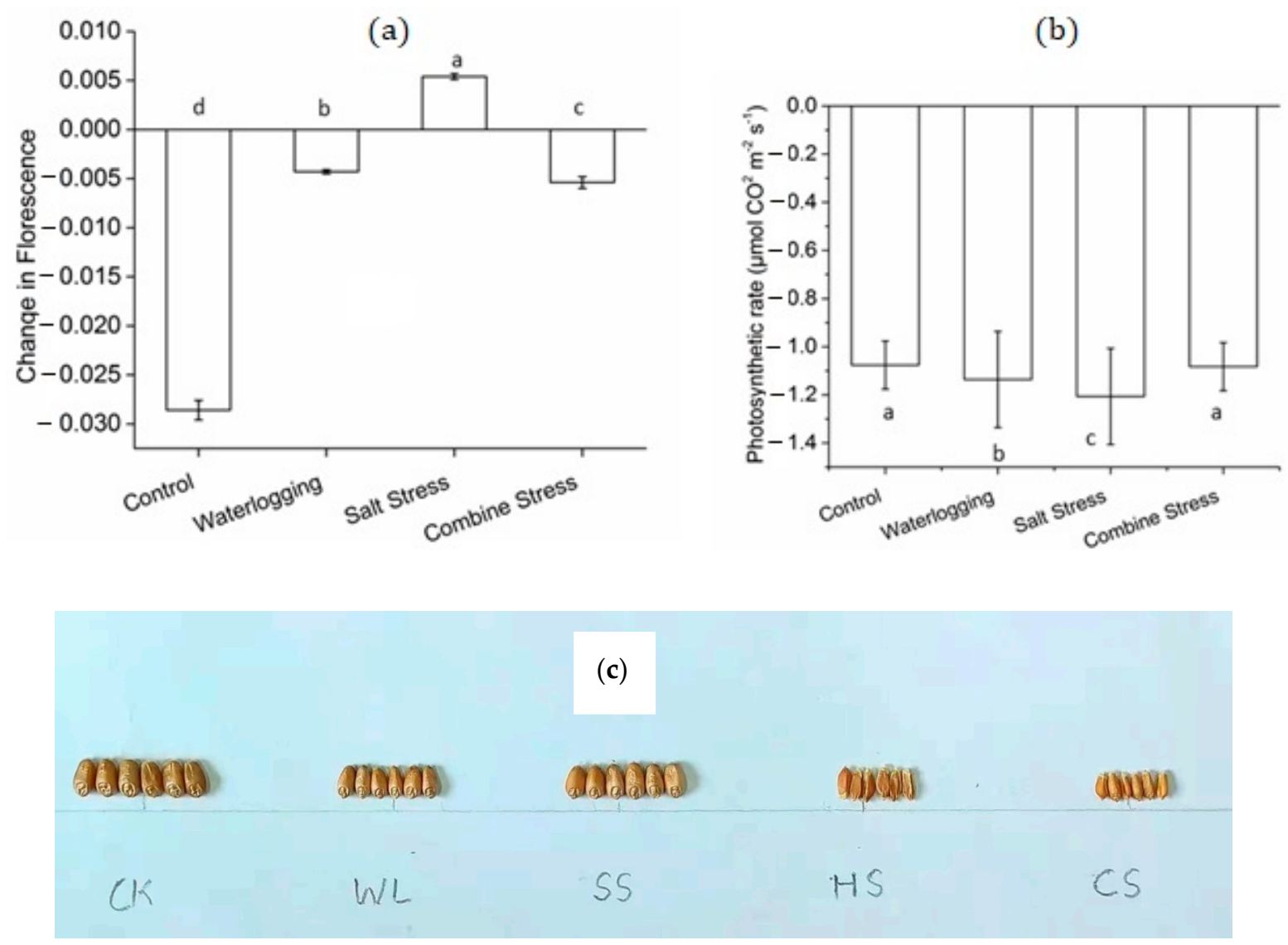

Figure 1. Change in the (a) fluorescence and (b) photosynthetic activity of the wheat plants from 15 April 2020 to 22 April 2021 (flowering stage) grown under different abiotic stresses. (c) The difference in the grain sizes after harvest. Note: reported values are the means and standard deviations of triplicates for each treatment (exact values are given in Table S1). Lowercase letters show the significant differences among treatments according to one-way ANOVA and DMRT, while the significance level was $p \leq 0.05$. CK: control; WL: waterlogging; SS: salt stress; HS: heat stress; CS: combined stress. 


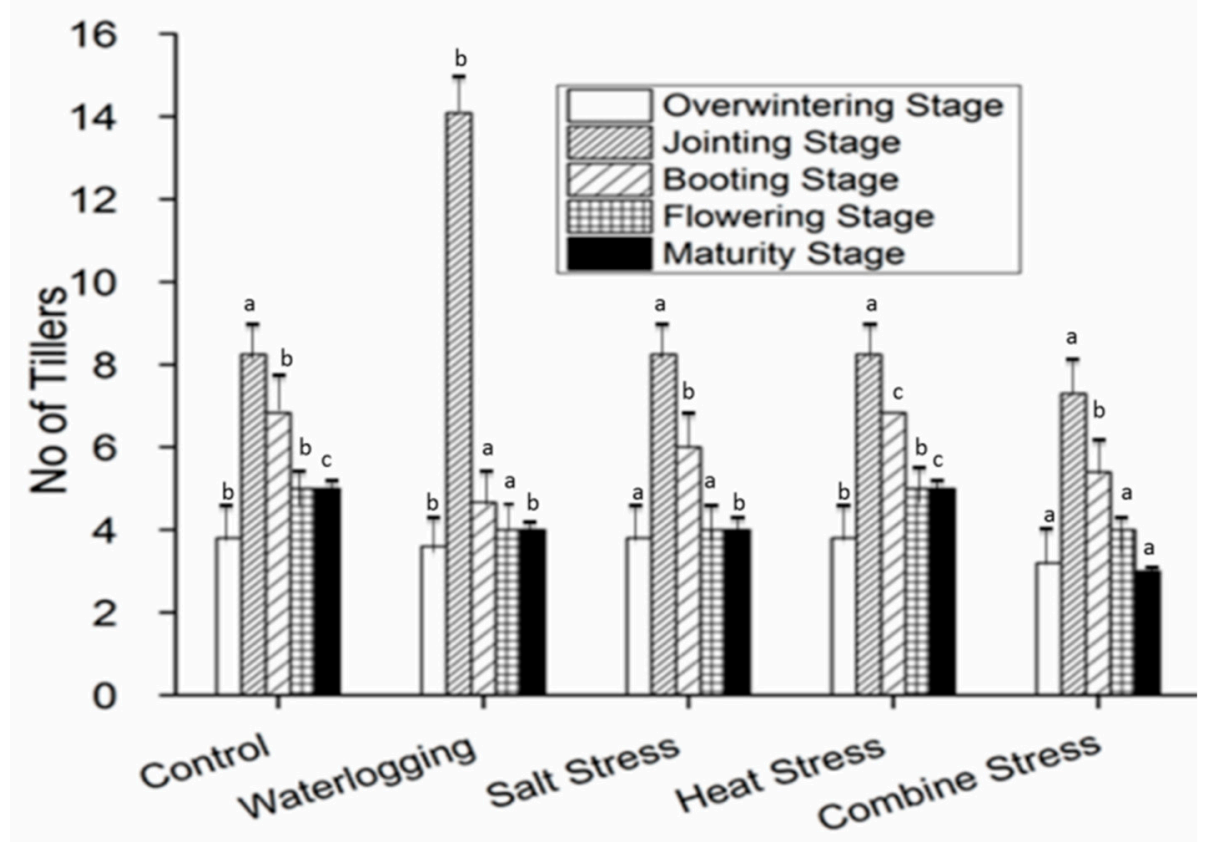

Figure 2. Number of tillers during five-stage growth of wheat plants grown under different abiotic stresses. Reported values are the means and standard deviations of triplicates for each treatment. Note: sampling date at overwintering stage was 28 December 2020; at jointing stage was 12 March 2021; at booting stage was 30 March 2021; at the flowering stage was 17 April 2021; and at maturity stage was 28 May 2021. Lowercase letters show the significant differences within treatments according to one-way ANOVA and DMRT, while the significance level was $p \leq 0.05$.

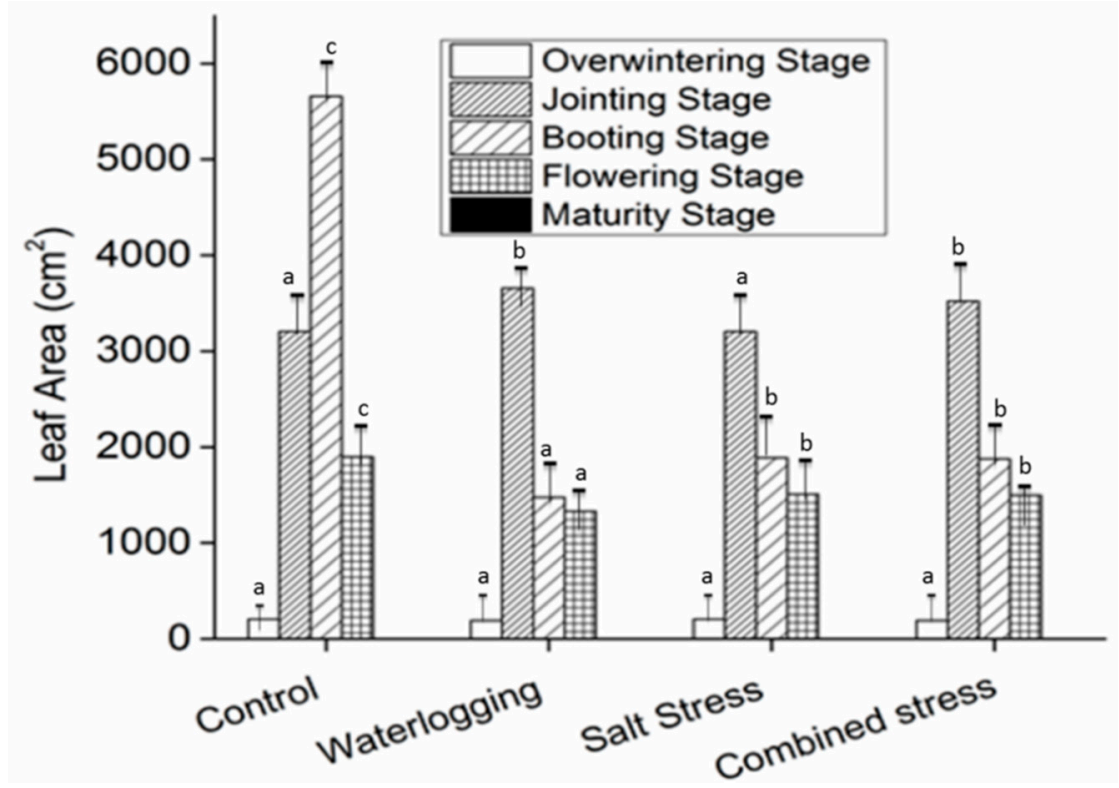

Figure 3. Leaf area of wheat plants during the five-stage plant growth (until flowering stage) grown under different abiotic stresses. Reported values are the means and standard deviations of triplicates for each treatment. Note: sampling date at overwintering stage was 28 December 2020; at jointing stage was 12 March 2021; at booting stage was 30 March 2021; at the flowering stage was 17 April 2021; and at maturity stage was 28 May 2021. Lowercase letters show the significant differences among treatments according to one-way ANOVA and DMRT, while the significance level was $p \leq 0.05$. 


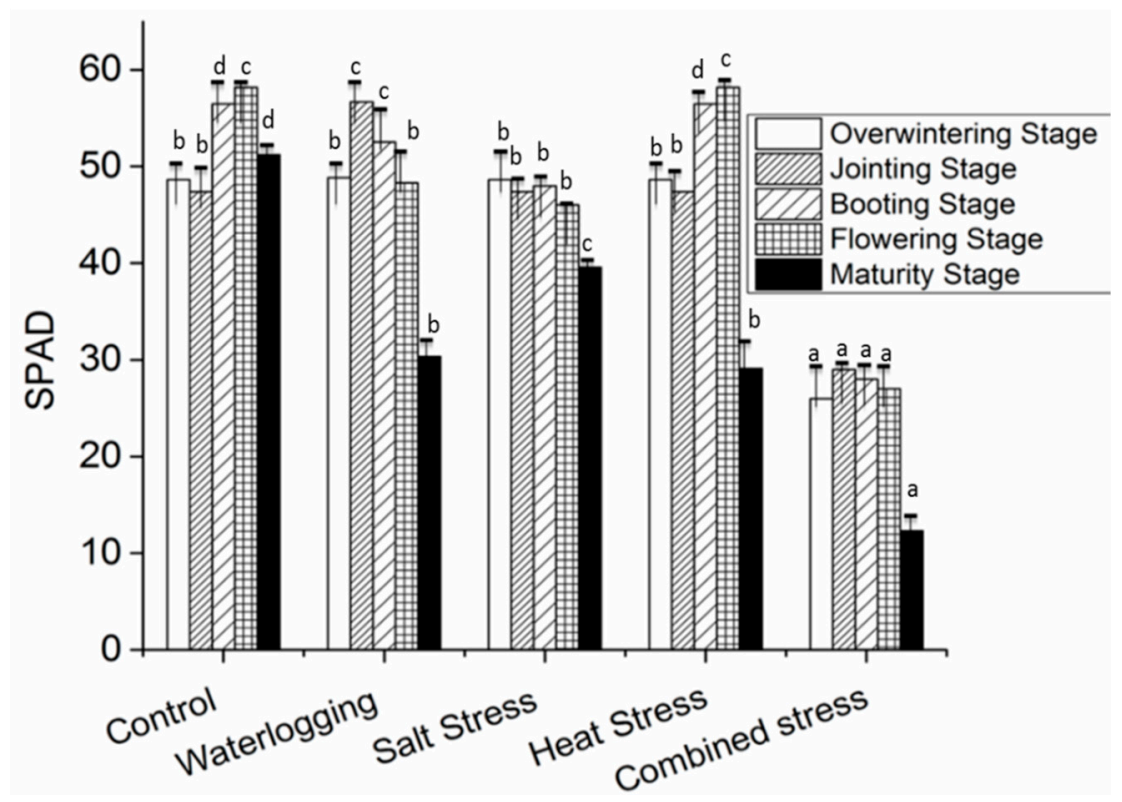

Figure 4. SPAD value of wheat plants during the five-stage growth of plants grown under different abiotic stresses. Reported values are the means and standard deviations of triplicates for each treatment. Note: sampling date at overwintering stage was 28 December 2020; at jointing stage was 12 March 2021; at booting stage was 30 March 2021; at the flowering stage was 17 April 2021; and at maturity stage was 28 May 2021. Lowercase letters show the significant differences among treatments according to one-way ANOVA and DMRT, while the significance level was $p \leq 0.05$.

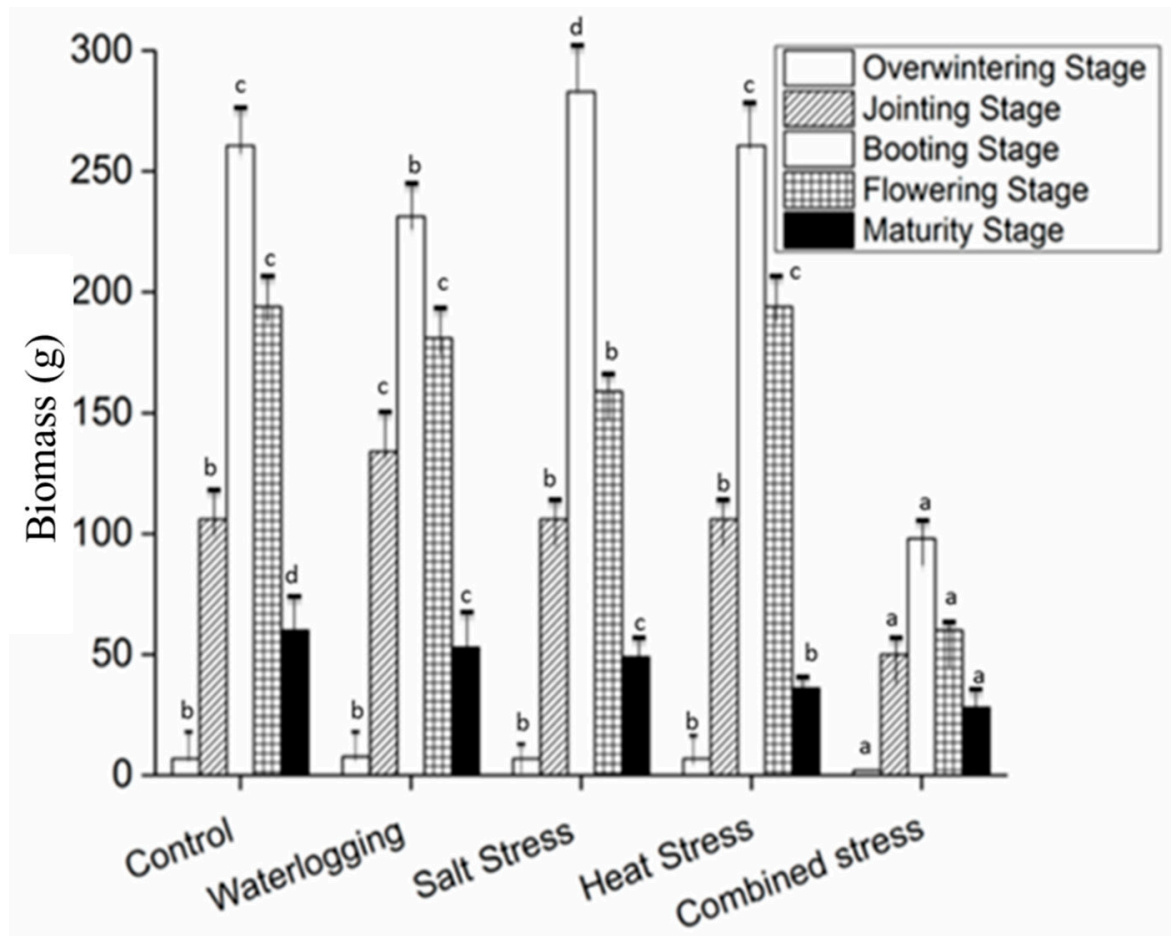

Figure 5. Fresh biomass of wheat plants during five-stage growth of plants grown under different abiotic stresses. Reported values are the means and standard deviations of triplicates for each treatment. Note: sampling date at overwintering stage was 28 December 2020; at jointing stage was 12 March 2021; at booting stage was 30 Mar 2021; at the flowering stage was 17 April 2021; and at maturity stage was 28 May 2021. Lowercase letters show the significant differences within treatments according to one-way ANOVA and DMRT, while the significance level was $p \leq 0.05$. 


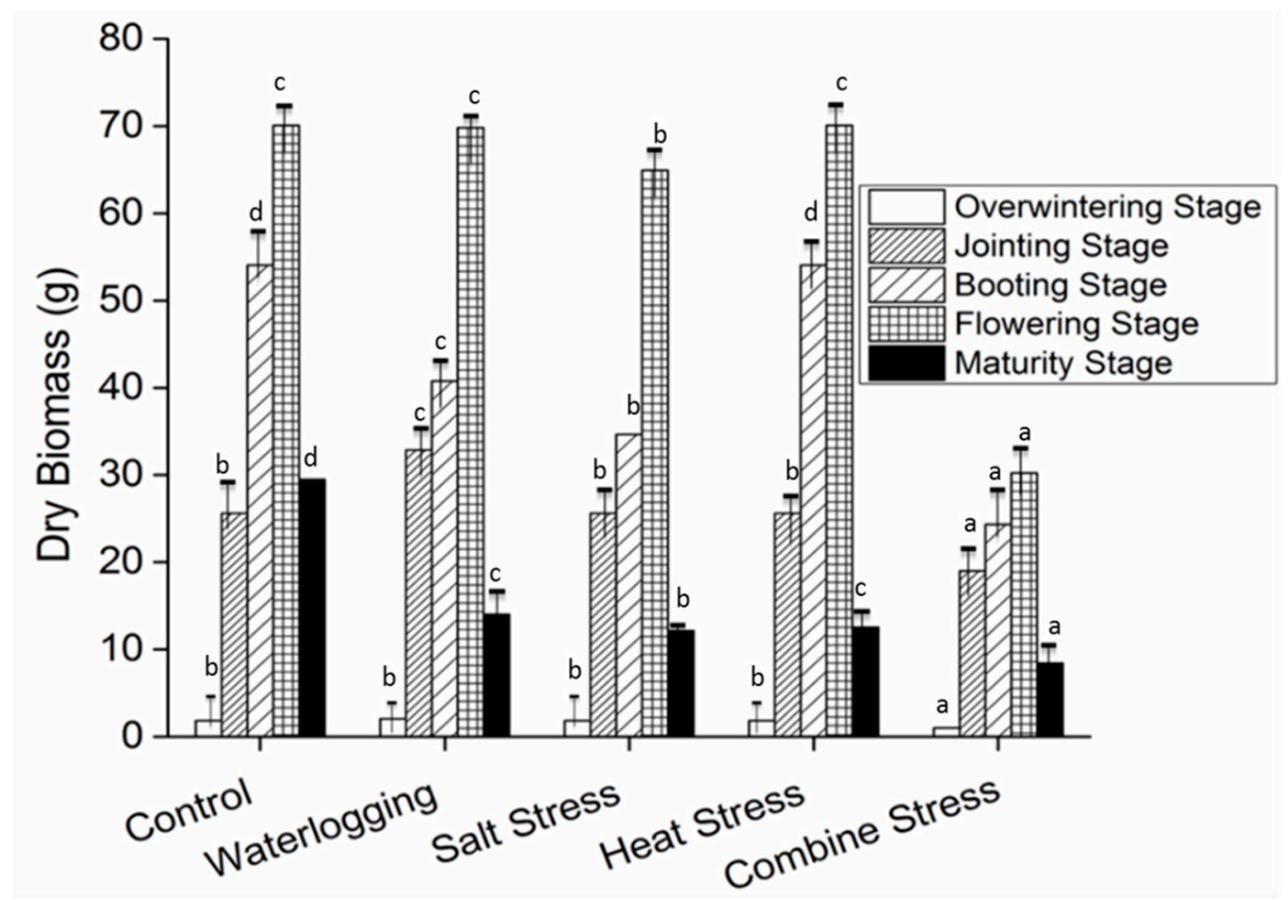

Figure 6. Dry biomass of wheat plants during the five-stage growth of plants grown under different abiotic stresses. Reported values are the means and standard deviations of triplicates for each treatment. Note: sampling date at overwintering stage was 28 December 2020; at jointing stage was 12 March 2021; at booting stage was 30 Mar 2021; at the flowering stage was 17 April 2021; and at maturity stage was 28 May 2021. Lowercase letters show the significant differences among treatments according to one-way ANOVA and DMRT, while the significance level was $p \leq 0.05$.

(a)

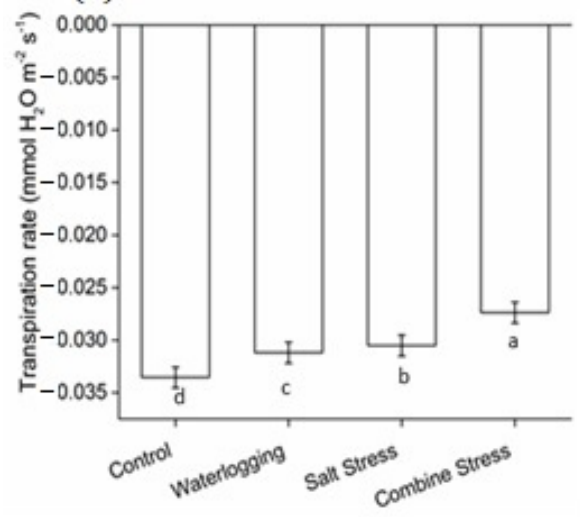

(b)

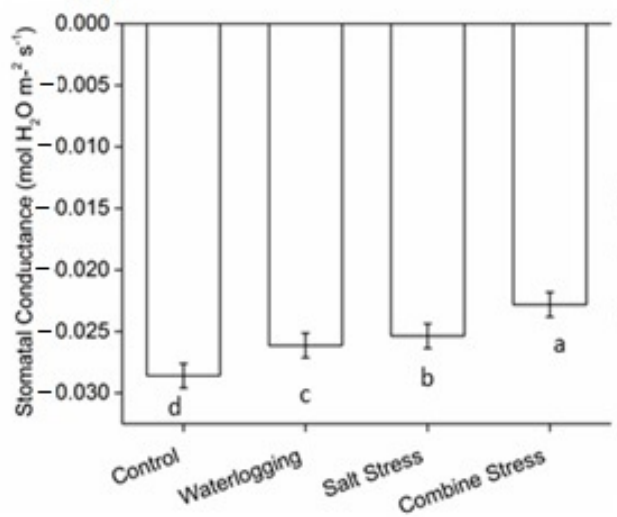

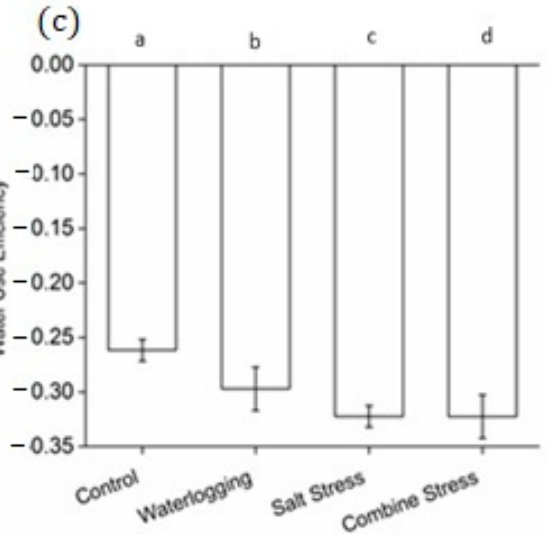

Figure 7. (a) Transpiration rate; (b) stomata conductance; and (c) water use efficiency of the wheat plants from 15 April 2020 to 22 April 2021 (flowering stage) grown under different abiotic stresses. Water use efficiency was measured in $\mu \mathrm{mol}$ $\mathrm{CO}_{2} \mathrm{~m}^{-2} \mathrm{~s}^{-1} / \mathrm{mmol} \mathrm{H}_{2} \mathrm{O} \mathrm{m}^{-2} \mathrm{~s}^{-1}$. Note: Reported values are the means and standard deviations of triplicates for each treatment (exact values are given in Table S1). Lowercase letters show the significant differences among treatments according to one-way ANOVA and DMRT, while the significance level was $p \leq 0.05$.

\subsubsection{Salt Stress and Wheat Growth during the Study}

The salt stress was applied after the jointing stage; initially, it was less disturbing for the plant, but the wheat growth was significantly $(p \leq 0.05)$ reduced after the booting stage. It was evident in the change in fluorescence value and photosynthetic rate (Figure $1 \mathrm{a}, \mathrm{b}$ ), which were 0.794 and $14.58 \mu \mathrm{mol} \mathrm{CO}_{2} \mathrm{~m}^{-2} \mathrm{~s}^{-1}$, respectively, at the start of the experiment in control. A significant decrease of 2 and $4 \%$ was observed in the case of florescence value 
and photosynthetic rate, respectively. It was also correlated with the number of tillers. Tillers and leaf area of the plant (Figures 2 and 3) were 6.8 and $3655 \mathrm{~cm}^{2}$ at the booting stage, respectively, and both were significantly $(p \leq 0.05)$ reduced at the flowering stage. The plant had four tillers in case of stress while the control had 5; the leaf area at this stage was $1898 \mathrm{~cm}^{2}$, while it was $1590 \mathrm{~cm}^{2}$ in salt stress conditions. The photosynthetic rate corresponded to the SPAD value, which showed a significant $(p \leq 0.05)$ decrease at the flowering stage (Figure 4). It was $\sim 57$ in the case of the control at the flowering stage, while it was reduced to $\sim 46$ once salt stress was applied. SPAD value is the measure of chlorophyll value. Both leaf area and photosynthetic rate were decreased significantly $(p \leq 0.05)$ by stress, resulting in significant reductions in total dry matter accumulation rates and final yields. The same trend of fresh and dry biomass was observed in our study, in which the application of stress considerably $(p \leq 0.05)$ reduced the biomass content of the wheat plant (Figures 5 and 6). This trend of photosynthetic rate was also correlated with the stomatal conductance (Figure $7 \mathrm{~b}$ ), transpiration rate (Figure 7a), and water use efficiency (Figure 7c). In April 2021, stressed wheat plants showed 8.9, 12, 9.8, and 8.9\% lower stomatal conductance, transpiration rate, intercellular $\mathrm{CO}_{2}$, and water use efficiency, respectively than control plants.

\subsubsection{Heat Stress and Wheat Growth during the Study}

The heat stress was applied after the flowering stage; it was significantly $(p \leq 0.05)$ most disturbing to the plant, perhaps due to the unavailability of nitrogen, as release time for most of the nitrogen in the case of SCU, is 120 days. The trend of fresh and dry biomass explains this in our study, in which stress application considerably $(p \leq 0.05)$ reduced the biomass content of the wheat plant (Figure 5). At the maturation phase, the biomass for control was $\sim 55 \mathrm{~g}$, while it was reduced to $25 \mathrm{~g}$ after heat stress. For all growth parameters, control plants grew better than stressed ones. However, the stress affected the wheat plant comparatively less until after the first $\sim 110$ days of the experiment (until the booting stage).

In contrast, afterward, growth was significantly affected $(p \leq 0.05)$. It can be explained in terms of the nitrogen release period of the SCU, which was $\sim 120$ days. Combined stress had quite the same action as heat stress.

\subsection{Plant Stress Response and Yield Aspects}

\subsubsection{Effect of Waterlogging Stress on Yield of the Wheat Plant}

Table 1 shows the effect of waterlogging stress on the yield of the wheat plant. The crop yield $\mathrm{kg} \mathrm{ha}^{-1}$ was reduced significantly ( $p \leq 0.05$ ) to 6034.5 , which was $\sim 40 \%$ less than the control group $\left(10,270 \mathrm{~kg} \mathrm{ha}^{-1}\right)$. It was $60 \%$ of the growth without stress. It is explainable in terms of the 1000-grain weight, which was reduced significantly $(p \leq 0.05)$ from $56 \mathrm{~g}$ in control to $46 \mathrm{~g}$ once the stress was applied.

Table 1. Influence of abiotic stresses on the wheat yields after harvest.

\begin{tabular}{ccccc}
\hline $\begin{array}{c}\text { Treatments/ } \\
\text { Parameters }\end{array}$ & $\begin{array}{c}\text { 1000 Grain } \\
\text { Weight } \mathbf{( g )}\end{array}$ & $\begin{array}{c}\text { Harvest Index } \\
\mathbf{( \% )}\end{array}$ & $\begin{array}{c}\text { Yield } \\
\text { (Mann/Acre) }\end{array}$ & Yield (kg ha $\left.\mathbf{~}^{-1}\right)$ \\
\hline Control & $56.75^{\mathrm{a}} \pm 2.30$ & $44.09^{\mathrm{d}} \pm 1.31$ & $103.90^{\mathrm{a}} \pm 2.65$ & $10270.10^{\mathrm{a}} \pm 14$ \\
Waterlogging & $46.95^{\mathrm{c}} \pm 2.12$ & $54.41^{\mathrm{b}} \pm 1.46$ & $61.05^{\mathrm{b}} \pm 1.31$ & $6034.50^{\mathrm{b}} \pm 08$ \\
Salt stress & $48.50^{\mathrm{b}} \pm 2.10$ & $56.96^{\mathrm{a}} \pm 1.23$ & $55.37^{\mathrm{c}} \pm 1.11$ & $5473.16^{\mathrm{c}} \pm 08$ \\
Heat stress & $21.95^{\mathrm{d}} \pm 1.10$ & $36.54^{\mathrm{e}} \pm 0.98$ & $36.66^{\mathrm{d}} \pm 1.09$ & $3623.47^{\mathrm{d}} \pm 09$ \\
Combined stress & $22.80^{\mathrm{d}} \pm 0.98$ & $34.82^{\mathrm{f}} \pm 1.08$ & $23.36^{\mathrm{f}} \pm 0.78$ & $2309.10^{\mathrm{f}} \pm 11$ \\
\hline
\end{tabular}

Note: lowercase letters show the significant differences among treatments according to one-way ANOVA and DMRT at a significance level of $p \leq 0.05$.

\subsubsection{Effect of Salt Stress on Yield of the Wheat Plant}

The effect of salt stress on the yield of the wheat plant is given in Table 1 . The crop yield $\mathrm{kg} \mathrm{ha}^{-1}$ was reduced significantly $(p \leq 0.05)$ to $5473.16 \mathrm{~kg} \mathrm{ha}^{-1}$. It was not significantly $(p \leq 0.05)$ less, but just half of the growth without stress, which was further correlated with 
the 1000-grain weight, which was reduced significantly $(p \leq 0.05)$ from $56 \mathrm{~g}$ in control to $48.50 \mathrm{~g}$ once the salt stress was applied.

\subsubsection{Effect of Heat Stress on Yield of the Wheat Plant}

In the case of heat stress, the crop yield was $3623.47 \mathrm{~kg} \mathrm{ha}^{-1}$, while in control, it was $10270 \mathrm{~kg} \mathrm{ha}^{-1}$ (Table 1). In other words, the crop yield was reduced by $75 \%$ after heat stress application. This was further related to the 1000-grain weight, which was reduced significantly $(p \leq 0.05)$ from $56 \mathrm{~g}$ in control to $21.50 \mathrm{~g}$ once the stress was applied. The heat stress was significantly $(p \leq 0.05)$ more deadly for the plant than salt and waterlogging stress, as shown in Table 1.

\subsubsection{Effect of Combined Stress on Yield of the Wheat Plant}

Table 1 shows the effect of combined stress on the yield of the wheat plant. The crop yield $\mathrm{kg} \mathrm{ha}^{-1}$ was reduced significantly $(p \leq 0.05)$ from 10,270 in the control group to 2309.10 in the stressed one. The 1000-grain weight was significantly $(p \leq 0.05)$ reduced from $56.75 \mathrm{~g}$ in control to $22.80 \mathrm{~g}$ in stress conditions.

The correlation matrix (Table 2) shows the negative correlation between spike number and grain weight. The leaf area, photosynthesis, SPAD, tiller, and spike weight were positively correlated. The PCA matrix and plot (Table 3 and Figure 8) show the spike length, spike weight, and leaf area as the most prominent parameters affecting plant yield once the leaf area was reduced, which might have been due to the waterlogging stress. As a result, photosynthesis was reduced, and ultimately, spike weight was compromised. On the other hand, once spike weight was compromised, ultimately, grain weight was reduced, and finally, the plant yield was reduced. 
Table 2. Correlation between morphological attributes of the wheat plants grown under abiotic stresses.

\begin{tabular}{|c|c|c|c|c|c|c|c|c|c|c|c|c|c|c|c|c|c|c|c|}
\hline Correlation & PH & $\mathrm{T}$ & LA & SPAD & S.P & SL & SW & S.S & GW.S & G.S & IGW & TGW & GY.P & B.P & HI & Ymann.ac & Ykg.ha & Pearson & Color \\
\hline $\mathrm{PH}$ & & 0.357 & 0.148 & 0.89 & 0.293 & -0.075 & 0.531 & -0.051 & 0.481 & 0.064 & 0.782 & 0.789 & 0.649 & 0.634 & 0.24 & 0.649 & 0.649 & -1 & \\
\hline $\mathrm{T}$ & 0.185 & & 0.816 & 0.513 & 0.891 & 0.521 & 0.396 & 0.519 & 0.307 & 0.233 & 0.292 & 0.276 & 0.591 & 0.652 & -0.002 & 0.591 & 0.591 & -0.5 & \\
\hline SPAD & 0.943 & 0.463 & 0.257 & & 0.321 & -0.049 & 0.663 & -0.05 & 0.67 & 0.108 & 0.939 & 0.934 & 0.736 & 0.623 & 0.585 & 0.737 & 0.737 & 0.5 & \\
\hline S.P & 0.12 & 0.904 & 0.598 & 0.359 & & 0.439 & 0.175 & 0.435 & 0.049 & 0.083 & 0.098 & 0.113 & 0.469 & 0.601 & -0.274 & 0.469 & 0.469 & 1 & \\
\hline SL & 0.029 & 0.679 & 0.943 & 0.143 & 0.478 & & 0.554 & 0.997 & 0.435 & 0.866 & -0.108 & -0.145 & 0.556 & 0.67 & -0.326 & 0.555 & 0.555 & & \\
\hline SW & 0.371 & 0.494 & 0.829 & 0.429 & 0.239 & 0.714 & & 0.534 & 0.981 & 0.799 & 0.737 & 0.708 & 0.94 & 0.844 & 0.45 & 0.94 & 0.94 & & \\
\hline S.S & -0.029 & 0.626 & 0.899 & 0.058 & 0.485 & 0.986 & 0.638 & & 0.408 & 0.854 & -0.127 & -0.165 & 0.538 & 0.666 & -0.368 & 0.538 & 0.538 & & \\
\hline GW.S & 0.429 & 0.216 & 0.657 & 0.371 & 0 & 0.6 & 0.943 & 0.551 & & 0.735 & 0.788 & 0.758 & 0.88 & 0.732 & 0.607 & 0.88 & 0.88 & & \\
\hline G.S & 0.429 & 0.216 & 0.657 & 0.371 & 0 & 0.6 & 0.943 & 0.551 & 1 & & 0.188 & 0.148 & 0.688 & 0.697 & 0 & 0.687 & 0.687 & & \\
\hline IGW & 0.883 & 0.334 & 0.412 & 0.883 & 0.123 & 0.294 & 0.736 & 0.194 & 0.736 & 0.736 & & 0.997 & 0.738 & 0.557 & 0.763 & 0.739 & 0.739 & & \\
\hline TGW & 0.943 & 0.185 & 0.257 & 0.886 & 0 & 0.2 & 0.6 & 0.116 & 0.657 & 0.657 & 0.971 & & 0.726 & 0.547 & 0.751 & 0.726 & 0.726 & & \\
\hline GY.P & 0.486 & 0.617 & 0.714 & 0.6 & 0.478 & 0.486 & 0.886 & 0.406 & 0.771 & 0.771 & 0.765 & 0.6 & & 0.957 & 0.315 & 1 & 1 & & \\
\hline $\mathrm{HI}$ & 0.429 & 0 & -0.029 & 0.486 & -0.239 & -0.257 & 0.371 & -0.406 & 0.314 & 0.314 & 0.618 & 0.543 & 0.486 & 0.086 & & 0.315 & 0.315 & & \\
\hline Ymann.ac & 0.486 & 0.617 & 0.714 & 0.6 & 0.478 & 0.486 & 0.886 & 0.406 & 0.771 & 0.771 & 0.765 & 0.6 & 1 & 0.886 & 0.486 & & 1 & & \\
\hline Ykg.ha & 0.486 & 0.617 & 0.714 & 0.6 & 0.478 & 0.486 & 0.886 & 0.406 & 0.771 & 0.771 & 0.765 & 0.6 & 1 & 0.886 & 0.486 & 1 & & & \\
\hline $\begin{array}{c}\text { Spearman } \\
\text { Values }\end{array}$ & -1 & -0.5 & 0 & 0.5 & 1 & & & & & & & & & & & & & & \\
\hline Color & & & & & & & & & & & & & & & & & & & \\
\hline
\end{tabular}

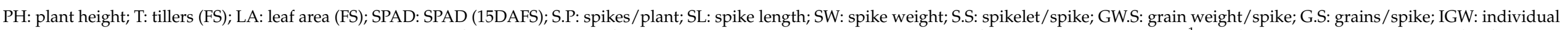

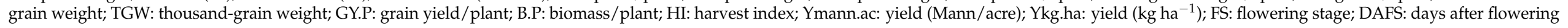
stage. 
Table 3. Principal component analysis between morphology and abiotic stress responses.

\begin{tabular}{ccc}
\hline Pattern Matrix & Component 1 & Component 2 \\
\hline SL & 1.091 & -0.424 \\
S.S & 1.091 & -0.441 \\
LA & 0.942 & \\
G.S & 0.865 & \\
B.P & 0.749 & 0.361 \\
T & 0.662 & \\
S.P & 0.628 & \\
GY.P & 0.587 & 0.584 \\
Ymann.ac & 0.587 & 0.584 \\
Ykg.ha & 0.587 & 0.584 \\
TGW & & 1.07 \\
IGW & & 1.062 \\
SPAD & & 0.973 \\
HI & -0.463 & 0.882 \\
PH & & 0.834 \\
GW.S & 0.371 & 0.685 \\
SW & 0.523 & 0.595 \\
\hline
\end{tabular}

Note: PH: plant height; T: tillers (FS); LA: leaf area (FS); SPAD: SPAD (15DAFS); S.P: spikes/plant; SL: spike length; SW: spike weight; S.S: spikelet/spike; GW.S: grain weight/spike; G.S: grains/spike; IGW: individual grain weight; TGW: thousand-grain weight; GY.P: grain yield/plant; B.P: biomass/plant; HI: harvest index; Ymann.ac: yield (Mann/acre); Ykg.ha: yield $\left(\mathrm{kg} \mathrm{ha}^{-1}\right)$; FS: flowering stage; DAFS: days after flowering stage.

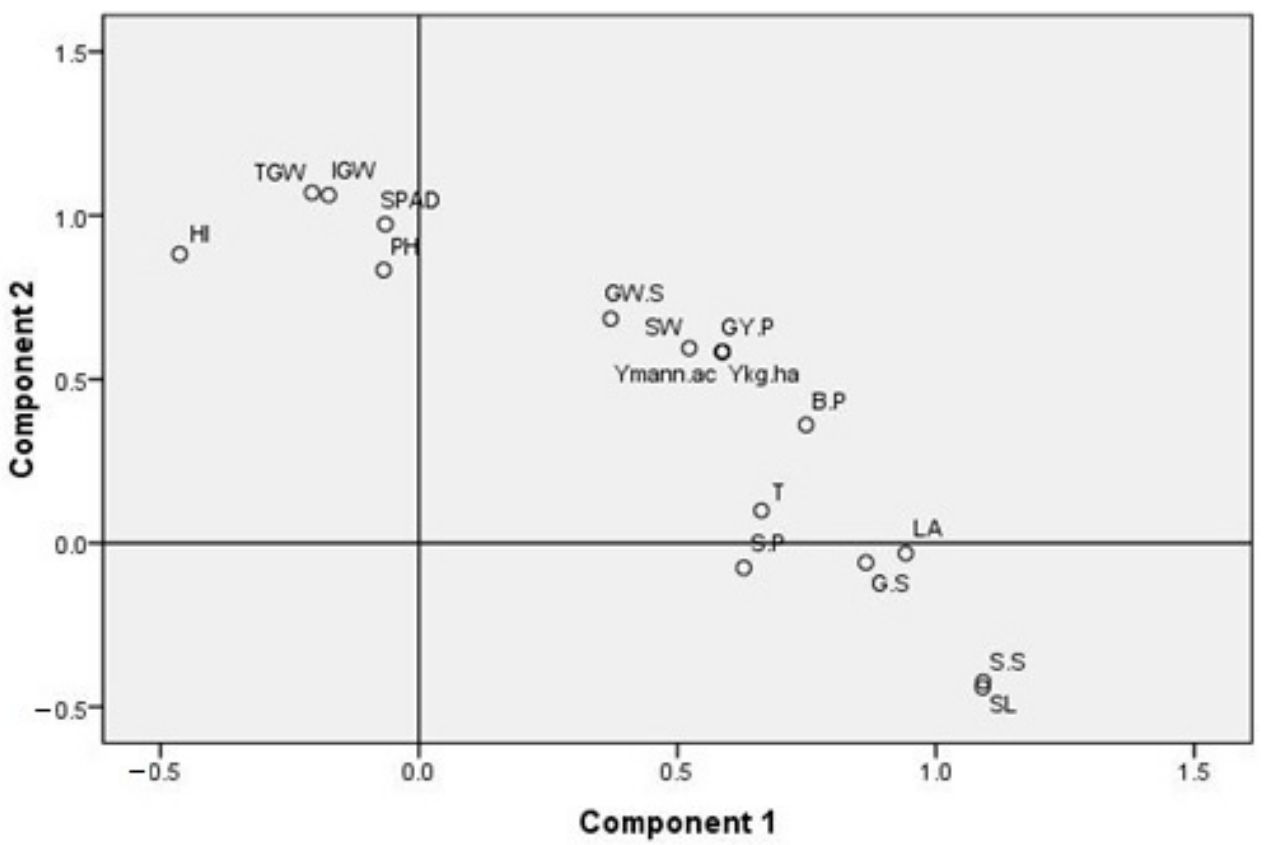

Figure 8. PCA plot showing chief components of plant stress responses. Note: PH: plant height; T: tillers (FS); LA: leaf area (FS); SPAD: SPAD (15DAFS); S.P: spikes/plant; SL: spike length; SW: spike weight; S.S: spikelet/spike; GW.S: grain weight/spike; G.S: grains/spike; IGW: individual grain weight; TGW: thousand-grain weight; GY.P: grain yield/plant; B.P: biomass/plant; HI: harvest index; Ymann.ac: yield (Mann/acre); Ykg.ha: yield $\left(\mathrm{kg} \mathrm{ha}^{-1}\right)$; FS: flowering stage; DAFS: days after flowering stage.

\subsubsection{NPK in the Plant and Stress Response}

Fertilizer is an essential resource for plant growth. The results of NPK in wheat plants grown under different abiotic stresses and with SCU application are shown in Table 4. It was revealed that NPK was highest in control and lowest in the case of heat and combined stresses. At the heat stress application stage, the plant was already at 
the flowering stage, and \%N was significantly $(p \leq 0.05)$ reduced from 2.8 to $1.8 \%, \mathrm{P}$ was reduced from $0.31 \mathrm{mg} / \mathrm{kg}$ to $0.24 \mathrm{mg} / \mathrm{kg}$, and \%K was reduced 1.2 to $0.98 \%$. A $20 \%$ decrease in $\% \mathrm{~K}$ was observed in waterlogging stress, and it was the same in all treatments. Combined stressed accumulated the least nitrogen $(1.33 \%)$ and $\mathrm{P}(0.98 \%)$ in plants among all treatments (Table 4).

Table 4. Phosphorous, potassium, and nitrogen accumulation in wheat plants grown under different abiotic stresses.

\begin{tabular}{ccccc}
\hline Treatments & $\mathbf{P}$ in Plant & K in Plant & $\mathbf{N}$ in Soil & N in Plant \\
\hline Control & $\mathbf{( m g / k g )}$ & $\mathbf{( \% )}$ & $\mathbf{( \% )}$ & $\mathbf{( \% )}$ \\
\hline Waterlogging & $0.31^{\mathrm{d}} \pm 0.01$ & $1.2^{\mathrm{d}} \pm 0.12$ & $0.08^{\mathrm{a}} \pm 0.001$ & $2.8^{\mathrm{d}} \pm 0.2$ \\
Salt stress & $0.26^{\mathrm{c}} \pm 0.02$ & $1.13^{\mathrm{c}} \pm 0.11$ & $0.09^{\mathrm{b}} \pm 0.002$ & $2.01^{\mathrm{c}} \pm 0.2$ \\
Heat stress & $0.25^{\mathrm{b}} \pm 0.02$ & $1.11^{\mathrm{b}} \pm 0.13$ & $0.08^{\mathrm{a}} \pm 0.002$ & $1.99^{\mathrm{c}} \pm 0.1$ \\
Combined Stress & $0.24^{\mathrm{b}} \pm 0.01$ & $1.09^{\mathrm{b}} \pm 0.09$ & $0.07^{\mathrm{a}} \pm 0.003$ & $1.89^{\mathrm{b}} \pm 0.12$ \\
\hline
\end{tabular}

Note: lowercase letters show the significant differences among treatments according to one-way ANOVA and DMRT at a significance level of $p \leq 0.05$.

\section{Discussion}

In the current experiment, the effect of different abiotic stresses was analyzed individually and in a combined form under the influence of SCU. It was found that the spike weight and root network were affected by all the stresses, but heat stress significantly $(p \leq 0.05)$ reduced crop yield (Table 1$)$. Our results of crop yield reduction due to heat stress were following the previous studies conducted on wheat and soya bean [7-9]. It was also found that the nitrogen release period was key to the stress alleviation for the plant at a growth point of $\sim 120$ days (that is, nitrogen release period of the fertilizer), as the plant was able to grow in all stressed environments. However, after this phase (at maturity and late flowering), plant growth was significantly $(p \leq 0.05)$ reduced. Our studies observed correlations between growth parameters, such as spike number and grain weight leaf area, photosynthesis, SPAD, tiller, and spike weight (Table 2). Studies in the past also revealed that different growth parameters were related to each other, and changes in one growth parameter could cause alterations in the other parameters of the wheat plant [32]. The PCA matrix and plot (Table 3 and Figure 8) show the spike length, spike weight, and leaf area as the most prominent parameters affecting crop yield. Many studies have suggested the dry weight of wheat seedlings as the best principle for measuring the stress resistance attribute of the genotype $[33,34]$. A further detailed discussion of these results is given below.

The stress (waterlogging, salt stress, and heat) tolerance in the wheat plants is a matter of growth tolerance in plants, which initiate vigorous root systems and proliferate abundantly $[1,2,33]$. Our experiments also showed fewer tillers and reduced photosynthetic rate, fluorescence, dry biomass, leaf area, SPAD value, and crop yield, especially for the heat and salt stresses. However, these effects were moderate in waterlogging stress, especially for the first 120 days (Table 1, Figures $2-4$ and 6). Salt stress was already reported to adversely affect plants' growth by Yu et al. [10]. In another study, Domico et al. [11] also reported reduced metabolic activity in the cardoon plant when subjected to long-term and short-term salt stress. The work of Pezo et al. further supported our results [12], reporting the reduced crop yield and pepper seed quality under salt stress.

Similarly, our results of reduced photosynthetic rate, leaf area, dry biomass, and yield were consistent with previous research conducted on wheat [7] and soya bean [8]. Waterlogging is undoubtedly reported to negatively impact a plant's physiological and biochemical response [16-18]. However, few studies also reported the innate adaptability of a plant against waterlogging stress [35]. It might be attributed to the capability of a plant to grow in hypoxic conditions that are mainly based on the root system tolerance of a plant $[18,35]$. It was hypothesized that the Yangmai 25 was able to build a good root network. That is why it was less affected by waterlogging stress than other stresses. In 
the first phase of waterlogging stress, the root growth might have been rapid or close to that of the control plants in Yangmai 25, but after 120 days, the growth of the roots might have been compromised, which resulted in the decreased crop yield (Table 1). Once the root growth is clasped, the shoot growth can never recover to the control value for any genotypes [35]. Malik et al. [36] also suggested root growth recovery as a key to waterlogging stress tolerance. Similar results were also revealed by Ahmed et al. [37] while working on mung bean under waterlogging stress.

Now let us find out why the plant tolerated the stress for the first 120 days. The answer lies in the nitrogen release time of the SCU used in the current study, which was 120 days. In the first phase, wheat could withstand all the stresses due to the soil's high accessibility of nutrients and water availability [33,34]. Our findings disclosed that crops reached maturity phases a bit early; this might be due to controlled release/coated fertilizer [20]. The experiment showed that the $\mathrm{N}$ released by SCU attained maximum nitrogen content in the control plants, followed by waterlogging, salt stress, combined, and then heat stress. Our results agreed with Praharaj et al. [38] and Joshi et al. [39], who worked on pulses and rice, respectively. These studies found that adequate irrigation and controlled nitrogen supplies could induce extra productivity in plants in abiotic stress conditions. The coated urea also helped the wheat plant attain better grain weight (1000-grain weight) than the control (Table 1), but fertilizer was the least effective in heat stress. Similar results of enhanced grain weight in the wheat plant were observed by Ghafoor et al. [22] while applying SCU to alleviate stress on the plant in an arid climate.

In our experiment, heat stress significantly $(p \leq 0.05)$ reduced plant growth among all stresses (Figures 2-6). This can be explained in terms of the heat sensitivity of the plant [8]. High-temperature stress is the leading environmental factor that limits wheat yield. Wheat yield decreases by $10 \%$ for every $1{ }^{\circ} \mathrm{C}$ increase above the mean temperature of $23{ }^{\circ} \mathrm{C}[6]$. High-temperature stress affects more than $40 \%$ of the world's wheat area every year. It reduces wheat yield through chronic stress resulting from prolonged, relatively high temperatures up to $32{ }^{\circ} \mathrm{C}$, or through heat-shock caused by abruptly but comparatively brief exposure to $33^{\circ} \mathrm{C}$ and above. High temperatures cause changes in the physiological, biochemical, and molecular components of wheat crops. The high temperature might have initially accelerated the thylakoid membrane breakdown, resulting in electrolyte leakage and disruption of all electrochemical processes, particularly photosystem II (PS II)and cytochrome $\mathrm{f} / \mathrm{b} 6$-mediated reactions have resulted in a drastic decrease in the photosynthesis rate $[40,41]$. Wheat's PS II is more exposed to extreme temperature stress, as it is a winter season crop instead of a warm-season crop, such as rice and pearl millet (Pennisetum glaucum) [42].

One argument can be further made based on photophosphorylation; high-temperature stress also tends to cause a halt in photophosphorylation due to thylakoid membrane damage [43]. The rate of photosynthetic $\mathrm{CO}_{2}$ assimilation was lower after stress application than in control (Figure 7b). This has previously been reported in various plant studies. The decrease in net photosynthesis could be attributed to changes in leaf water potential (Figure 7c), stomatal conductance (Figure 7b), the amount or activity of photosynthetic enzymes, and chlorophyll (Figure 4). According to some experiments, one possible factor in reducing photosynthesis in plants grown under heat stress is the accumulation of carbohydrates in leaves, indicating a feedback inhibition of photosynthesis $[43,44]$. Other studies have suggested that abiotic stress, particularly salt stress, reduces net respiratory activity in the roots, asserting a feedback mechanism that uses photosynthesis and inhibits plant growth $[45,46]$. Based on our findings, it appeared that stomatal closure may have contributed to the decreased photosynthetic rate in this experiment, particularly once the nitrogen source, i.e., SCU, was exhausted. Our results are supported by past literature, in which it was found that the nitrogen release timing of the fertilizer was key to the stress survival and nitrogen release from the slow-release fertilizer help in the recovery of the wheat plant once exposed to heat [8], salt stress [11], and waterlogging stress [17]. 
The wheat plant was able to grow under stress for the first 120 days. The controlled release of nitrogen fertilizer was key to the wheat plant growth, especially in waterlogged and salt stress. Many studies found that a higher grain yield can be attained by applying controlled-release SCU fertilization [23]. SCU increased grain yield efficiently by lowering rhizosphere $\mathrm{pH}$, and the results were consistent with findings of a previous study [47]. Our findings also showed that using SCU $\mathrm{N}$ at a rate of $130 \mathrm{~kg} \mathrm{ha}^{-1}$ resulted in better growth in the first 120 days in terms of leaf area, biomass gain, photosynthesis rate, fluorescence, SPAD value, etc. However, grain yield, number of grains per spike, grain weight, and harvest index were compromised. These results are supported by past studies that reported the effects of abiotic stress on cardoon [11], wheat genotype [32], and other cash crops [35].

The earlier phase of the experiment (120 days) revealed that controlled-release fertilizers increased total $\mathrm{N}$ percent with equal $\mathrm{N}$ level application vs. later stages once the nitrogen source, i.e., SCU, was exploited [22]. After stress application, grain yield was decreased by 9.58 to $11.21 \%$, and $\mathrm{N}$ uptake was reduced by 19.06 to $23.94 \%$ (Table 4 ). This was because protein contains nitrogen as an essential constituent, and $\mathrm{N}$ is involved in all vital processes of plants. For this reason, nitrogen application is both necessary and unavoidable for crop production [20]. The optimal soil $\mathrm{N}$ content increases photosynthetic processes, leaf area production, leaf area duration, and net assimilation rate [33,37]. Since crop yields have increased globally due to increased $\mathrm{N}$ use and good management practices [19], all plants, including cereals, oilseeds, fiber, and sugar-producing plants, require a balanced amount of nitrogen for vigorous growth and development in a larger harvest with higher quality. Nitrogen fertilization has also improved Pakistani crops' growth and yield parameters for crops such as wheat, rice, sugarcane, and cotton. Wheat growth and yield parameters such as plant height $(\mathrm{cm})$, number of tillers $\left(\mathrm{m}^{-2}\right)$, number of spikelets $\left(\right.$ spike $\left.^{-1}\right)$, grains (spike ${ }^{-1}$ ), and 1000-grain weight have been improved by nitrogen fertilization. Ali et al. [48] also demonstrated that coated urea fertilizer with higher nitrate contents and neem nitrification increased grain yield. Hence, SCU is effective under abiotic stresses once it can control nitrogen release but is no longer effective once the limit is reached. It is suggested to use a more advanced fertilizer with a better nitrogen release period of about 160 days.

Furthermore, screening should be done in soil rather than potting mix. The adverse effects in Vertosol soil were much more apparent and more representative of the actual situation on farms. The chlorophyll fluorescence model proved to be the most suitable for large-scale programs when choosing wheat genotypes for abiotic stress tolerance, requiring only a few seconds per sample. More specific studies at the cellular and tissue levels are needed to understand the fundamental physiological mechanisms fully.

\section{Conclusions}

The SCU fertilizer was applied at a recommended rate $\left(130 \mathrm{~kg} \mathrm{ha}^{-1}\right)$ to increase wheat stress tolerance. The experiment presented the positive possessions of SCU on wheat growth and development, physiological conditions, and nitrogen accumulation under different abiotic stress conditions. After 120 days, all stress types significantly $(p<0.05)$ reduced plant growth (leaf area, dry biomass, SPAD value, and the number of tillers). However, the crop yield was most compromised in the cases of heat and combined stress. The heat stress showed the lowest grain yield of $3623.47 \mathrm{~kg} \mathrm{ha}^{-1}$, while waterlogging stress showed a better yield of $6034.5 \mathrm{~kg} \mathrm{ha}^{-1}$ in all stresses.

SCU, used in the current study, has a controlled nitrogen release time that meets nitrogen requirements for up to 120 days only. Hence, the wheat plant was able to tolerate salt and waterlogging stress to some extent. However, once the nitrogen source was exhausted at the time of heat stress, the plant could not tolerate heat stress. Therefore, it is suggested to use SCU with a longer release time to provide nitrogen until the wheat reaches the harvesting stage. In this way, wheat growers, especially farmers in developing countries, can use sustainable ecosystem practices in the salt-affected soils. There is a need to conduct studies on SCU with a release period of $\sim 180$ days, particularly in heat 
stress conditions. Another future recommendation for the study is to analyze the nitrogen losses and ecosystem benefits while using slow-release SCU instead of common nitrogen fertilizers. Future research studies, such as modeling ecosystem services and $\mathrm{N}$ loss under various crop and climate change scenarios, may also indicate the agricultural system's sustainability.

Supplementary Materials: The following are available online at https://www.mdpi.com/article/10 .3390 /agronomy11112340/s1, Figure S1. Setups for the waterlogging stress (a), control/salt stress (b), and heat stress (c) experiments. Figure S2. Schematic representation of the experimental design. Figure S3. Time bar graph of the whole study. Table S1. Photosynthetic attributes of the wheat plant. Table S2. Properties of the soil used in the study.

Author Contributions: Conceptualization, formal analysis, investigation, methodology, software, validation, visualization, writing-original draft, A.A.; conceptualization, funding acquisition, methodology, project administration, supervision, writing-review and editing, X.Z. (Xinkai Zhu); conceptualization, methodology, resources, supervision, writing_review and editing, M.Z.; investigation, M.Q.; formal analysis, writing-review and editing, S.I.; investigation, D.X.; formal analysis, writing-review and editing, M.A.; writing-review and editing, X.Z. (Xinbo Zhang); writingreview and editing, S.G.; writing-review and editing, F.L.; writing-review and editing, A.Z.S.; writing-review and editing, A.Z. All authors have read and agreed to the published version of the manuscript.

Funding: This work was jointly supported by the earmarked fund for Jiangsu Agricultural Industry Technology System (JATS[2021]503), the National Key Research and Development Program of China (2018YFD0200500), the National Natural Science Foundation of China $(31901433,31771711)$, Jiangsu Modern Agricultural (Wheat) Industry Technology System, Pilot Projects of the Central Cooperative Extension Program for Major Agricultural Technologies, The Priority Academic Program Development of Jiangsu Higher Education Institutions, and The Science and Technology Innovation Team of Yangzhou University, Yangzhou, China.

Institutional Review Board Statement: Not applicable.

Informed Consent Statement: Not applicable.

Conflicts of Interest: The authors declare no conflict of interest.

\section{References}

1. Ding, J.; Huang, Z.; Zhu, M.; Li, C.; Zhu, X.; Guo, W. Does cyclic water stress damage wheat yield more than a single stress? PLoS ONE 2018, 13, e0195535. [CrossRef] [PubMed]

2. Liu, L.; Xia, Y.; Liu, B.; Chang, C.; Xiao, L.; Shen, J.; Tang, L.; Cao, W.; Zhu, Y. Individual and combined effects of jointing and booting low-temperature stress on wheat yield. Eur. J. Agron. 2020, 113, 125989. [CrossRef]

3. Anosheh, H.P.; Emam, Y.; Ashraf, M.; Foolad, M. Exogenous application of salicylic acid and chlormequat chloride alleviates negative effects of drought stress in wheat. Adv. Stud. Biol. 2012, 4, 501-520.

4. Searchinger, T.; Hanson, C.; Ranganathan, J.; Lipinski, B.; Waite, R.; Winterbottom, R.; Dinshaw, A.; Heimlich, R.; Boval, M.; Chemineau, P. Creating a Sustainable Food Future: A Menu of Solutions to Feed Nearly 10 Billion People by 2050; Final Report; WRI: Washington, DC, USA, 2019.

5. Altaf, A.; Gull, S.; Zhu, X.; Zhu, M.; Rasool, G.; Ibrahim, M.E.H.; Aleem, M.; Uddin, S.; Saeed, A.; Shah, A.Z. Study of the effect of peg-6000 imposed drought stress on wheat (Triticum aestivum L.) cultivars using relative water content (RWC) and proline content analysis. Pak. J. Agric. Sci. 2021, 58, 357-367.

6. Prasad, P.V.; Pisipati, S.; Ristic, Z.; Bukovnik, U.; Fritz, A. Impact of nighttime temperature on physiology and growth of spring wheat. Crop. Sci. 2008, 48, 2372-2380. [CrossRef]

7. Sattar, A.; Sher, A.; Ijaz, M.; Ul-Allah, S.; Rizwan, M.S.; Hussain, M.; Jabran, K.; Cheema, M.A. Terminal drought and heat stress alter physiological and biochemical attributes in flag leaf of bread wheat. PLoS ONE 2020, 15, e0232974.

8. Cohen, I.; Zandalinas, S.I.; Fritschi, F.B.; Sengupta, S.; Fichman, Y.; Azad, R.K.; Mittler, R. The impact of water deficit and heat stress combination on the molecular response, physiology, and seed production of soybean. Physiol. Plant. 2021, 172, 41-52. [CrossRef]

9. Zahra, N.; Shaukat, K.; Hafeez, M.B.; Raza, A.; Hussain, S.; Chaudhary, M.T.; Akram, M.Z.; Kakavand, S.N.; Saddiq, M.S.; Wahid, A. Physiological and Molecular Responses to High, Chilling, and Freezing Temperature in Plant Growth and Production: Consequences and Mitigation Possibilities. In Harsh Environment and Plant Resilience; Springer: Berlin, Germany, 2021 ; p. 235.

10. Yu, G.; Zhang, X.; Ma, H. Changes in the physiological parameters of SbPIP1-transformed wheat plants under salt stress. Int. J. Genom. 2015, 2015, 384356. 
11. Docimo, T.; De Stefano, R.; Cappetta, E.; Piccinelli, A.L.; Celano, R.; De Palma, M.; Tucci, M. Physiological, biochemical, and metabolic responses to short and prolonged saline stress in two cultivated cardoon genotypes. Plants 2020, 9, 554. [CrossRef]

12. Pezo, C.; Valdebenito, S.; Flores, M.F.; Oyanedel, E.; Vidal, K.; Neaman, A.; Peñaloza, P. Impact of Mother Plant Saline Stress on the Agronomical Quality of Pepper Seeds. J. Soil Sci. Plant Nutr. 2020, 20, 2600-2605. [CrossRef]

13. Benidire, L.; El Khalloufi, F.; Oufdou, K.; Barakat, M.; Tulumello, J.; Ortet, P.; Heulin, T.; Achouak, W. Phytobeneficial bacteria improve saline stress tolerance in Vicia faba and modulate microbial interaction network. Sci. Total Environ. 2020, $729,139020$. [CrossRef]

14. Galicia-Campos, E.; Ramos-Solano, B.; Montero-Palmero, M.; Gutierrez-Mañero, F.J.; García-Villaraco, A. Management of Plant Physiology with Beneficial Bacteria to Improve Leaf Bioactive Profiles and Plant Adaptation under Saline Stress in Olea europea L. Foods 2020, 9, 57. [CrossRef]

15. Bhusal, N.; Lee, M.; Han, A.R.; Han, A.; Kim, H.S. Responses to drought stress in Prunus sargentii and Larix kaempferi seedlings using morphological and physiological parameters. For. Ecol. Manag. 2020, 465, 118099. [CrossRef]

16. Wu, L.; Han, X.; Islam, S.; Zhai, S.; Zhao, H.; Zhang, G.; Cui, G.; Zhang, F.; Han, W.; You, X. Effects of sowing mode on lodging resistance and grain yield in winter wheat. Agronomy 2021, 11, 1378. [CrossRef]

17. Wang, X.; He, Y.; Zhang, C.; Tian, Y.-a.; Lei, X.; Li, D.; Bai, S.; Deng, X.; Lin, H. Physiological and transcriptional responses of Phalaris arundinacea under waterlogging conditions. J. Plant Physiol. 2021, 261, 153428. [CrossRef]

18. Bhusal, N.; Kim, H.S.; Han, S.-G.; Yoon, T.-M. Photosynthetic traits and plant-water relations of two apple cultivars grown as bi-leader trees under long-term waterlogging conditions. Environ. Exp. Bot. 2020, 176, 104111. [CrossRef]

19. Zörb, C.; Ludewig, U.; Hawkesford, M.J. Perspective on wheat yield and quality with reduced nitrogen supply. Trends Plant Sci. 2018, 23, 1029-1037. [CrossRef]

20. Agami, R.A.; Alamri, S.A.; Abd El-Mageed, T.; Abousekken, M.; Hashem, M. Role of exogenous nitrogen supply in alleviating the deficit irrigation stress in wheat plants. Agric. Water Manag. 2018, 210, 261-270. [CrossRef]

21. Gooding, M.; Pinyosinwat, A.; Ellis, R. Responses of wheat grain yield and quality to seed rate. J. Agric. Sci. 2002, 138, 317-331. [CrossRef]

22. Ghafoor, I.; Habib-ur-Rahman, M.; Ali, M.; Afzal, M.; Ahmed, W.; Gaiser, T.; Ghaffar, A. Slow-release nitrogen fertilizers enhance growth, yield, NUE in wheat crop and reduce nitrogen losses under an arid environment. Environ. Sci. Pollut. Res. 2021, 28, 43528-43543. [CrossRef]

23. Eghbali Babadi, F.; Yunus, R.; Abbasi, A.; Masoudi Soltani, S. Response surface method in the optimization of a rotary panequipped process for increased efficiency of slow-release coated urea. Processes 2019, 7, 125. [CrossRef]

24. Watson, M. Plant Analysis Handbook: A Practical Sampling, Preparation, Analysis, and Interpretation Guide; Micro Macro International Inc.: Athens, GA, USA, 1992; Volume 1, p. 82.

25. Chen, Z.; Zhou, M.; Newman, I.A.; Mendham, N.J.; Zhang, G.; Shabala, S. Potassium and sodium relations in salinised barley tissues as a basis of differential salt tolerance. Funct. Plant Biol. 2007, 34, 150-162. [CrossRef] [PubMed]

26. Wang, Z.-M.; Wei, A.-L.; Zheng, D.-M. Photosynthetic characteristics of non-leaf organs of winter wheat cultivars differing in ear type and their relationship with grain mass per ear. Photosynthetica 2001, 39, 239-244. [CrossRef]

27. Lu, Y.; Yan, Z.; Li, L.; Gao, C.; Shao, L. Selecting traits to improve the yield and water use efficiency of winter wheat under limited water supply. Agric. Water Manag. 2020, 242, 106410. [CrossRef]

28. Jixin, W.C.L. Spectraphotometry with Vanadium Phosphomolybdate-Nile Blue Multicomponent Complex and Determination of Vanadium in Monomineral Silicate. Chin. J. Anal. Chem. 1984, 10, 37-40.

29. Olsen, S.R. Estimation of Available Phosphorus in Soils by Extraction with Sodium Bicarbonate; US Department of Agriculture: Washington, DC, USA, 1954.

30. WHEELER, O.H.; MATEOS, J.L. The Ultraviolet Absorption of Isolated Double Bonds1. J. Org. Chem. 1956, 21, 1110-1112. [CrossRef]

31. d Steel, R.G.; Torrie, J.H. Principles and Procedures of Statistics: A Biometrical Approach; McGraw-Hill: New York, NY, USA, 1986.

32. Schirrmann, M.; Giebel, A.; Gleiniger, F.; Pflanz, M.; Lentschke, J.; Dammer, K.-H. Monitoring agronomic parameters of winter wheat crops with low-cost UAV imagery. Remote Sens. 2016, 8, 706. [CrossRef]

33. Ahmed, H.G.M.-D.; Zeng, Y.; Yang, X.; Anwaar, H.A.; Mansha, M.Z.; Hanif, C.M.S.; Ikram, K.; Ullah, A.; Alghanem, S.M.S. Conferring drought-tolerant wheat genotypes through morpho-physiological and chlorophyll indices at seedling stage. Saudi J. Biol. Sci. 2020, 27, 2116-2123. [CrossRef]

34. Ahmed, H.G.M.-D.; Sajjad, M.; Li, M.; Azmat, M.A.; Rizwan, M.; Maqsood, R.H.; Khan, S.H. Selection criteria for drought-tolerant bread wheat genotypes at seedling stage. Sustainability 2019, 11, 2584. [CrossRef]

35. Ahmed, F.; Rafii, M.; Ismail, M.R.; Juraimi, A.S.; Rahim, H.; Asfaliza, R.; Latif, M.A. Waterlogging tolerance of crops: Breeding, mechanism of tolerance, molecular approaches, and future prospects. BioMed Res. Int. 2013, 2013, 963525. [CrossRef]

36. Malik, A.I.; Colmer, T.D.; Lambers, H.; Schortemeyer, M. Changes in physiological and morphological traits of roots and shoots of wheat in response to different depths of waterlogging. Funct. Plant Biol. 2001, 28, 1121-1131. [CrossRef]

37. Ahmed, S.; Nawata, E.; Sakuratani, T. Effects of waterlogging at vegetative and reproductive growth stages on photosynthesis, leaf water potential and yield in mungbean. Plant Prod. Sci. 2002, 5, 117-123. [CrossRef]

38. Praharaj, C.; Singh, U.; Singh, S.; Singh, N.; Shivay, Y. Supplementary and life-saving irrigation for enhancing pulses production, productivity and water-use efficiency in India. Indian J. Agron. 2016, 61, 249-261. 
39. Joshi, R.; Sahoo, K.K.; Tripathi, A.K.; Kumar, R.; Gupta, B.K.; Pareek, A.; Singla-Pareek, S.L. Knockdown of an inflorescence meristem-specific cytokinin oxidase-OsCKX2 in rice reduces yield penalty under salinity stress condition. Plant Cell Environ. 2018, 41, 936-946. [CrossRef]

40. Sarkar, J.; Chakraborty, B.; Chakraborty, U. Plant growth promoting rhizobacteria protect wheat plants against temperature stress through antioxidant signalling and reducing chloroplast and membrane injury. J. Plant Growth Regul. 2018, 37, 1396-1412. [CrossRef]

41. Pospíšil, P. Production of reactive oxygen species by photosystem II as a response to light and temperature stress. Front. Plant Sci. 2016, 7, 1950. [CrossRef] [PubMed]

42. Brestic, M.; Zivcak, M. PSII fluorescence techniques for measurement of drought and high temperature stress signal in crop plants: Protocols and applications. In Molecular Stress Physiology of Plants; Springer: Berlin, Germany, 2013; pp. 87-131.

43. Narayanan, S. Membrane Fluidity and Compositional Changes in Response to High Temperature Stress in Wheat. In Physiological, Molecular, and Genetic Perspectives of Wheat Improvement; Springer: Cham, Switzerland, 2021; pp. 115-123.

44. Morsy, M.R.; Jouve, L.; Hausman, J.-F.; Hoffmann, L.; Stewart, J.M. Alteration of oxidative and carbohydrate metabolism under abiotic stress in two rice (Oryza sativa L.) genotypes contrasting in chilling tolerance. J. Plant Physiol. 2007, 164, $157-167$. [CrossRef] [PubMed]

45. Hasanuzzaman, M.; Bhuyan, M.; Zulfiqar, F.; Raza, A.; Mohsin, S.M.; Mahmud, J.A.; Fujita, M.; Fotopoulos, V. Reactive oxygen species and antioxidant defense in plants under abiotic stress: Revisiting the crucial role of a universal defense regulator. Antioxidants 2020, 9, 681. [CrossRef] [PubMed]

46. Demirel, U.; Morris, W.L.; Ducreux, L.J.; Yavuz, C.; Asim, A.; Tindas, I.; Campbell, R.; Morris, J.A.; Verrall, S.R.; Hedley, P.E. Physiological, biochemical, and transcriptional responses to single and combined abiotic stress in stress-tolerant and stress-sensitive potato genotypes. Front. Plant Sci. 2020, 11, 169. [CrossRef]

47. Shivay, Y.; Pooniya, V.; Prasad, R.; Pal, M.; Bansal, R. Sulphur-coated urea as a source of sulphur and an enhanced efficiency of nitrogen fertilizer for spring wheat. Cereal Res. Commun. 2016, 44, 513-523. [CrossRef]

48. Ali, K.; Munsif, F.; Zubair, M.; Hussain, Z.; Shahid, M.; Din, I.U.; Khan, N. Management of organic and inorganic nitrogen for different maize varieties. Sarhad J. Agric. 2011, 27, 525-529. 